\title{
Severe coagulopathy after a massasauga rattlesnake bite
}

\author{
Marissa Laureano MD, Mark Crowther MD
}

Cite as: CMAJ 2018 February 20;190:E191-4. doi: 10.1503/cmaj.170783

A healthy 25-year-old man was bitten by an eastern massasauga rattlesnake (Sistrurus catenatus; Figure 1) on his left great toe. He had been walking outside at night in open-toed sandals in the Eastern Georgian Bay region of Ontario. He developed lower leg edema, and pain and swelling around his great toe, but he delayed seeking medical treatment for 22 hours (Figure 2A).

On initial examination, the patient had a hemorrhagic bleb two puncture marks $1.5 \mathrm{~cm}$ apart on his great toe. $A 12 \mathrm{~cm} \times 6 \mathrm{~cm}$ hematoma was also present inferior to his left groin. Initial blood work showed an international normalized ratio of greater than 12.5 (normal range $0.9-1.1$ ), partial thromboplastin time of greater than 180 (normal range 20-40) s and fibrinogen of less than 0.6 (normal range 5.1-11.8) $\mu \mathrm{mol} / \mathrm{L}$. His hemoglobin level and platelet count were within normal limits.

In accordance with the West Parry Sound Health Centre algorithm for rattlesnake bites, he received one vial of Antivipmyn, followed by an additional nine vials. ${ }^{1}$ (Test doses are given to allow monitoring for anaphylaxis.) His international normalized ratio and partial thromboplastin time 3.5 hours after administration of antivenom improved to 2.4 and 45 seconds, respectively.

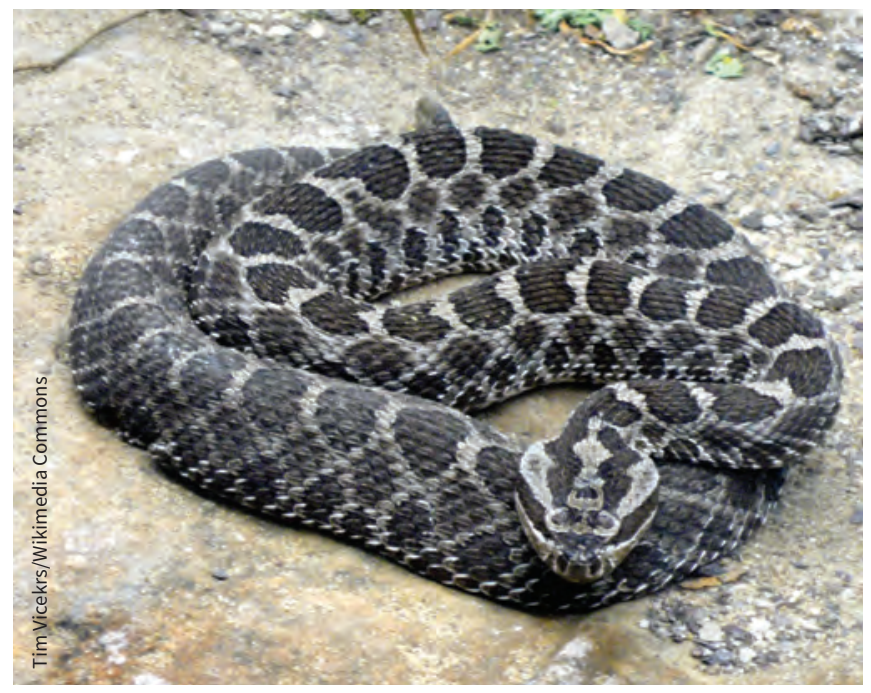

Figure 1: The massasauga rattlesnake is characterized by its blotching pattern throughout its gray to dark brown body. Its head is triangular and its vertical pupils differentiate it from other snakes in Ontario.

\section{KEY POINTS}

- Local injury, pain or swelling is concerning for envenomation after a rattlesnake bite.

- Monitoring for coagulopathies is required after massasauga rattlesnake bites.

- Antivenom is the first-line treatment for envenomation.

- Additional doses of antivenom may be needed; thus, close monitoring is required.

He was monitored in the intensive care unit and given an additional 10 vials of antivenom because of his ongoing pain, swelling and coagulopathy. This was followed by maintenance dosing with 12 vials of antivenom over 18 hours as his symptoms and coagulopathy began to improve.

The patient did not have any severe bleeding, and after 40 hours, the local swelling and erythema had improved substantially (Figure 2B). His international normalized ratio normalized to 1.1 and his partial thromboplastin time was 31 seconds (Box 1 ). Aside from antivenom, additional treatment (blood products or vitamin K) was not administered. He was discharged after four days of monitoring, during which time he received a total of 32 vials of Antivipmyn.

\section{Discussion}

The only venomous snake in Ontario, the massasauga rattlesnake resides mainly in the Eastern Georgian Bay area and the Bruce Peninsula (Figure 3). ${ }^{2}$ The Committee on the Status of Endangered Wildlife in Canada (COSEWIC) considers the snake to be threatened and it is protected under federal and provincial laws. Rattlesnake bites are uncommon, but potentially devastating. Envenomation can result in hemorrhage, increased vascular permeability, tissue necrosis and, in the worst-case scenario, death from shock. ${ }^{3}$ In a case reported by the Arizona Poison and Drug Information Center, a massasauga rattlesnake bit a 62-yearold man on the right thumb. That patient's fibrinogen decreased to less than $1.47 \mu \mathrm{mol} / \mathrm{L}$, but there were no other abnormalities in coagulation laboratory work. He did not have any bleeding and his fibrinogen levels normalized over two months. ${ }^{4}$ 


\section{Pathophysiology}

Venom-related coagulopathy can affect almost any component of the hemostatic system, and snakebites have been associated with platelet dysfunction, vessel wall breakdown, prothrombin overactivation and fibrinogen degradation. ${ }^{5,6}$ The nature of snake venom is complex, and a proteomic-based analysis of eastern massasauga venom showed the presence of metalloproteinases, L-amino acid oxidase, phospholipase A2 enzymes and serine proteases. ${ }^{7}$

Coagulopathy can recur after initial treatment with antivenom. The mechanism is not clearly understood, but it is thought to be a result of the clearance of the antivenom and a subsequent reappearance of the venom's effects. ${ }^{8}$ Venom can also be deposited as a depot at the site of the bite, resulting in lingering, unneutralized venom. ${ }^{8}$

\section{Management of rattlesnake bites}

To prevent rattlesnake bites, it is important to wear ankle-height, closed-toed boots or shoes when hiking in areas with rattle-

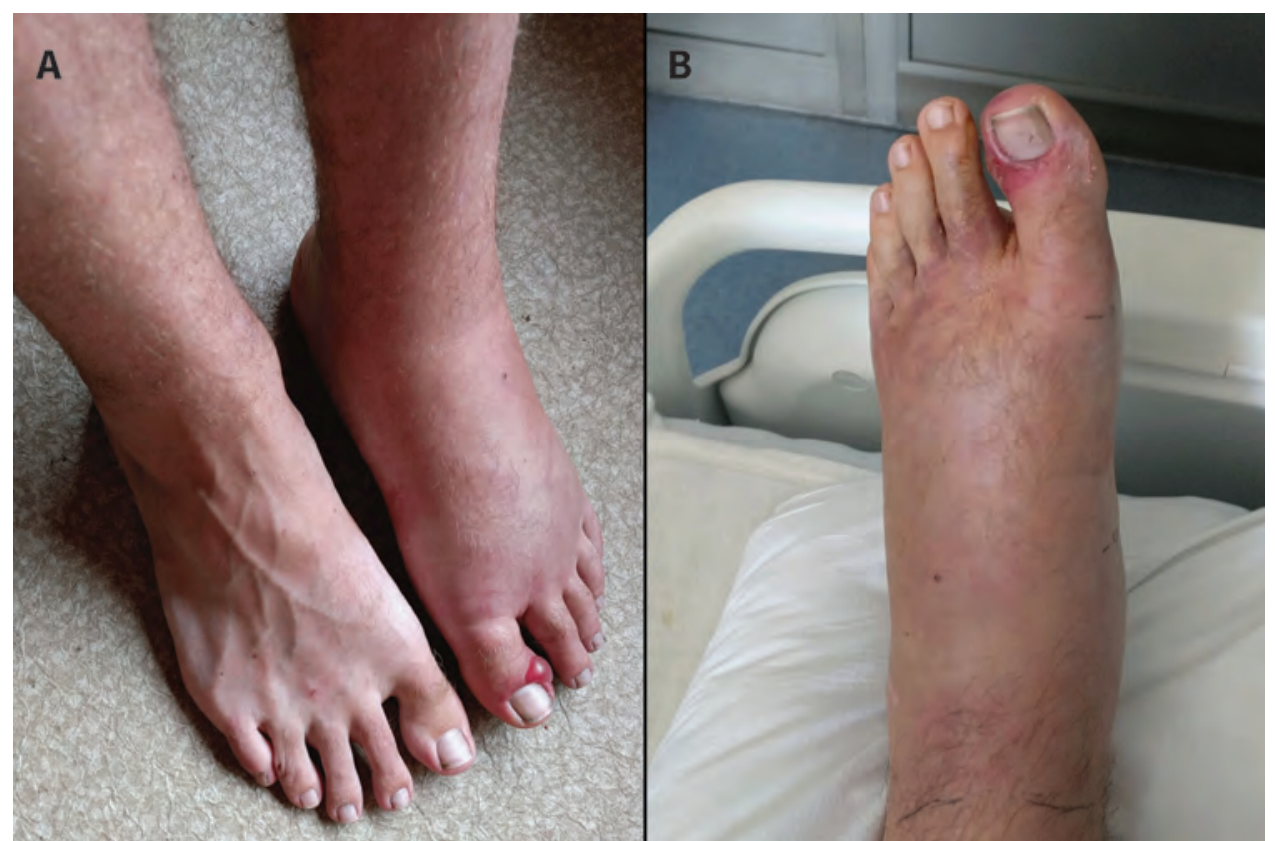

Figure 2: A 25-year-old man with a hemorrhagic bleb located on the left hallux with concomitant swelling and erythema of the lower left leg. The image in (A) was taken before treatment with antivenom, 12 hours after the bite. Figure 2B shows substantial improvement in the patient's erythema and edema 40 hours after the bite. By this time, 24 vials of antivenom had been administered.

\section{Box 1: Results of the patient's coagulation laboratory testing over time}

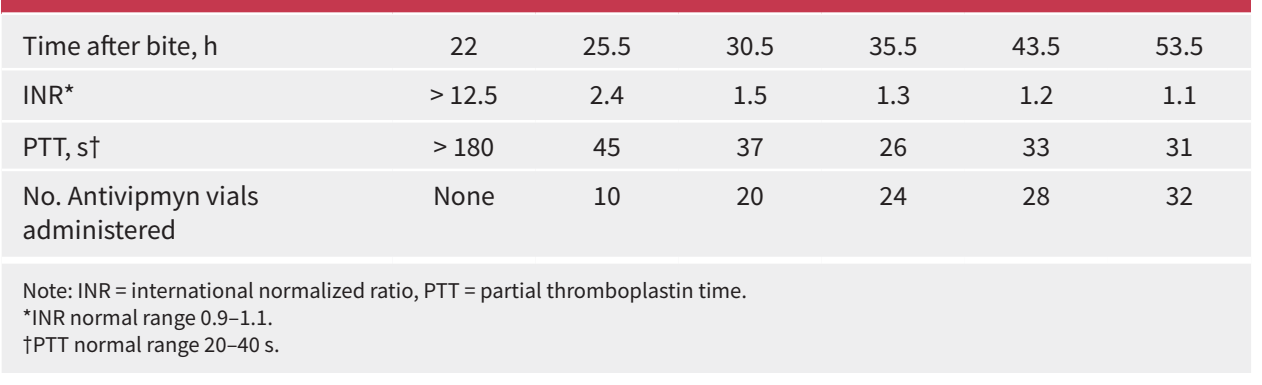

snakes. The massasauga has relatively small fangs, which are not likely to penetrate leather hiking boots or loose clothing. ${ }^{1,9}$

Initial first aid should focus on supporting the patient's airway, breathing and circulation. ${ }^{10}$ Tourniquets, ice and attempts at venom removal should be avoided and, because of the possibility of swelling, accessories such as rings or watches should be removed. Tetanus boosters should be given for prophylaxis. ${ }^{1}$ Unless a wound infection is present, there is no role for antibiotics in the treatment of rattlesnake bites. ${ }^{9}$

Antibodies to snake venoms (antivenom) are the most efficacious treatment for viper envenomation (pit vipers are a family of snakes that includes rattlesnakes). Massasauga rattlesnake envenomation can be treated with Antivipmyn, $a \mathrm{~F}\left(a b^{\prime}\right)_{2}$ fragment produced in horses. It has a relatively long half-life of 133 ( \pm standard deviation 52.53) $\mathrm{h}^{11}$ and reduced risk of rebound envenomation compared with other products. Recurrent coagulopathy has been reported after treatment with Fab antivenom in about one-third to one-half of patients. ${ }^{12,13}$ Antivenom is rotated through multiple facilities including municipal zoos, The Hospital for Sick Children in Toronto and hospitals near areas where massasauga rattlesnakes are known to reside. In Ontario, the West Parry Sound Health Centre acts as the provincial antivenom depot. Local poison control centres should be involved for rattlesnake envenomation, as they can provide direction regarding treatment and can facilitate the provision of antivenom.

Patients without pain, swelling or abnormalities in their laboratory work may have a "dry bite," meaning that no venom was injected. "Dry bites" comprise about $25 \%$ of bites and do not require antivenom; ${ }^{10}$ these patients should be carefully monitored in hospital for at least 8 hours, and ideally 24 hours, as signs of envenomation can be delayed. ${ }^{14}$ Serial measurements of limb circumference should be taken and laboratory work, including a complete blood count, coagulation parameters and fibrinogen, should be measured at the initial assessment. These blood tests should be repeated before discharge from hospital to ensure there are no signs of envenomation. ${ }^{14}$ Careful attention to the development of coagulopathy should be given when local injury is present. 


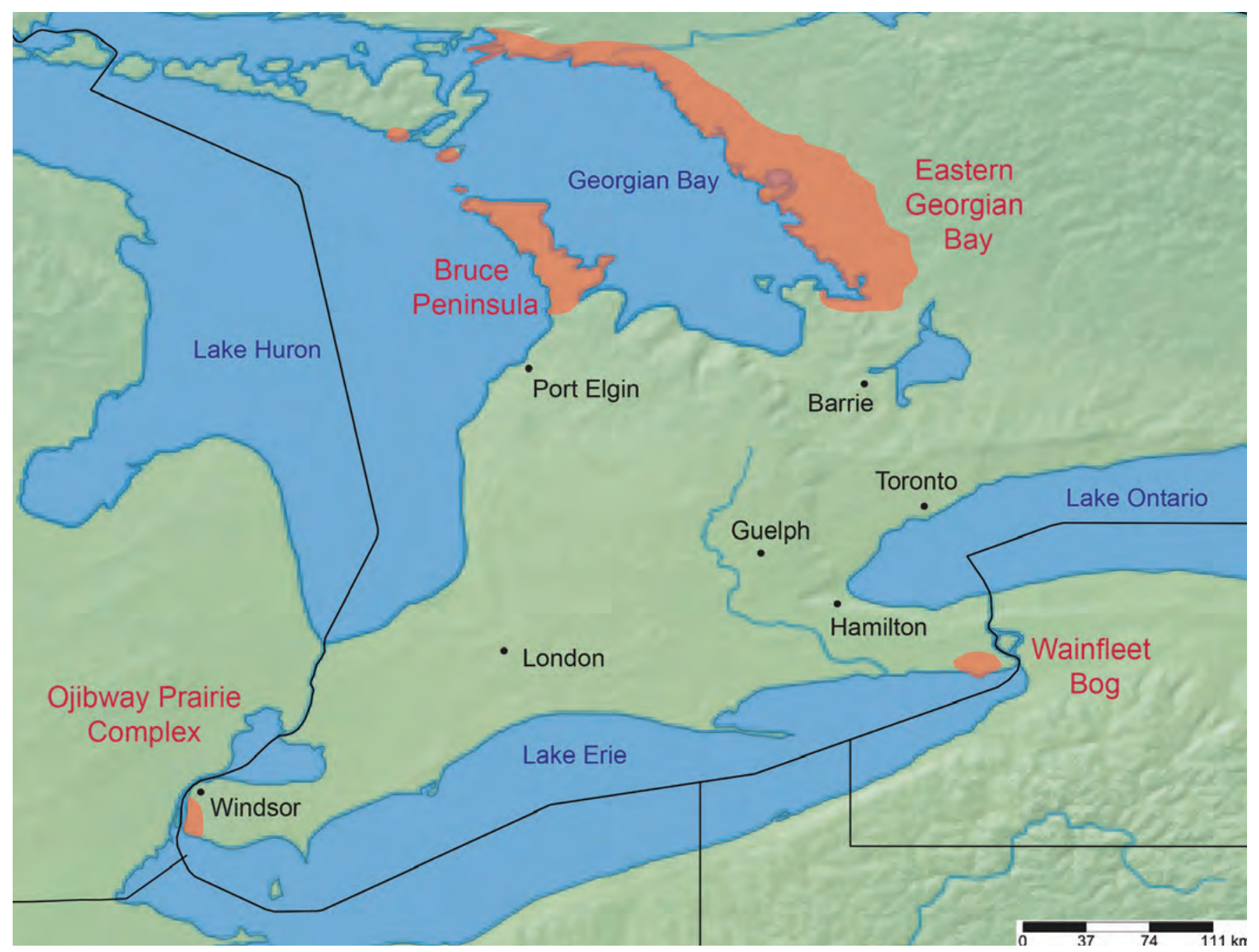

Figure 3: Geographic distribution of the massasauga rattlesnake in Ontario. Four major areas have been highlighted: Eastern Georgian Bay, Bruce Peninsula, Wainfleet Bog and Ojibway Prairie Complex. The patient in this case was bitten in the Eastern Georgian Bay area. Adapted from "Recovery Strategy for the massasauga (Sistrurus Catenatus) in Canada," Parks Canada Agency, 2015.

Antivenom should be administered to patients with signs and symptoms of envenomation. Therapy with antivenom should be titrated to the patient's pain, swelling and laboratory values. Laboratory work including a complete blood count, electrolytes, creatinine, urea, glucose, creatine kinase, international normalized ratio, aspartate transaminase and alanine transaminase should be measured two hours after each dose of antivenom. ${ }^{1}$ Persistent pain or swelling, thrombocytopenia and coagulopathy are indications for further treatment. ${ }^{1}$ As symptoms and laboratory values improve, maintenance dosing of antivenom can be given and the frequency of bloodwork can be decreased. ${ }^{1}$

Upon discharge, patients should be counselled regarding reasons to seek medical attention. They should return to an emergency department if they have bleeding, worsening pain, swelling or signs of infection. Patients should avoid contact sports, elective surgery and dental work for two weeks after the bite. ${ }^{1}$ To assess for late coagulopathy, a follow-up visit with bloodwork should be scheduled two to three days and five to seven days after discharge. ${ }^{14}$

\section{References}

1. Fargher T. Antivipmyn treatment package for eastern massasauga rattlesnake bites. Parry Sound (ON): West Parry Sound Health Centre, The Ontario Massasauga Rattlesnake Antivenom Depot 2011;21. Available: www.wpshc.com/ index.php/ontario-antivenom-depot-117 (accessed 2017 May 31).

2. Recovery strategy for the massasauga (Sistrurus catenatus) in Canada. Species Risk Act Recovery Strategy Series. Ottawa: Parks Canada Agency; 2012.

3. Juckett G, Hancox JG. Venomous snakebites in the United States: management review and update. Am Fam Physician 2002;65:1367-74.

4. Burgess JL, Dart RC. Snake venom coagulopathy: use and abuse of blood products in the treatment of pit viper envenomation. Ann Emerg Med 1991;20:795-801.

5. Isbister GK. Procoagulant snake toxins: laboratory studies diagnosis, and understanding snakebite coagulopathy. Semin Thromb Hemost 2009;35:93-103.

6. Meier J, Stocker K. Effects of snake venoms on hemostasis. Crit Rev Toxicol 1991;21:171-82.

7. Lisle Gibbs H, Chiucchi JE. Deconstructing a complex molecular phenotype: population-level variation in individual venom proteins in eastern massasauga rattlesnakes (Sistrurus c. catenatus). J Mol Evol 2011;72:383-97.

8. Seifert SA, Boyer LV. Recurrence phenomena after immunoglobulin therapy for snake envenomations: Part 1. Pharmacokinetics and pharmacodynamics of immunoglobulin antivenoms and related antibodies. Ann Emerg Med 2001;37:189-95. 
9. Junghanss T, Bodio M. Medically important venomous animals: biology, prevention, first aid, and clinical management. Clin Infect Dis 2006;43:1309-17.

10. Gold BS, Dart RC, Barish RA. Bites of venomous snakes. N Engl J Med 2002;347:347-56.

11. Garza-Ocanas L, Alagon A, Tamez de la O E, et al. Pharmacokinetic of Antivipmyn in healthy human volunteers. Toxicol Lett 2011;205(Suppl):S87.

12. Boyer LV, Seifert SA, Clark RF, et al. Recurrent and persistent coagulopathy following pit viper envenomation. Arch Intern Med 1999:159:706-10.
13. Bush SP, Ruha A-M, Seifert SA, et al. Comparison of $F\left(a b^{\prime}\right)_{2}$ versus Fab antivenom for pit viper envenomation: a prospective, blinded, multicenter, randomized clinical trial. Clin Toxicol (Phila) 2015;53:37-45.

14. Lavonas EJ, Ruha A-M, Banner W, et al.; Rocky Mountain Poison and Drug Center Denver Health and Hospital Authority. Unified treatment algorithm for the management of crotaline snakebite in the United States: results of an evidenceinformed consensus workshop. BMC Emerg Med 2011;11:2.
Competing interests: Within the last 48 months, Mark Crowther has sat on advisory boards for Octapharma, Bayer, Boehringer Ingelheim, Janssen, Pfizer, LEO Pharma and Portola; participated in study steering committees, or other research-related activities for projects involving AKP America, Daiichi, Bayer and LEO Pharma; received a Career Investigator award from the Heart and Stroke Foundation of Ontario; and held the LEO Pharma Chair in Thromboembolism Research at McMaster University (income from which is used to support the salary of research employees). His institutions (McMaster University and St Joseph's Healthcare) have received funding for research projects from the Heart and Stroke Foundation of Canada, LEO Pharma and Bayer for work in which Mark Crowther is involved. He has also received funding for preparation of educational materials and presentations from Alexion, Ortho Clinical Diagnostics, the BMS-Pfizer Alliance, LEO Pharma, AbbVie, Bayer, Celgene, Shire and CSL Behring, and participated in various medicolegal activities relating to thrombosis, anticoagulant drugs, or other aspects of hematological practice, and that these activities are bound by confidentiality arrangements. No other competing interests were declared.

This article has been peer reviewed.

The authors have obtained patient consent.

Affiliations: Departments of Medicine (Laureano), and Pathology and Molecular
Medicine (Laureano, Crowther), Faculty of Health Sciences, McMaster University, Hamilton, Ont.

Contributors: Both authors contributed to the conception and design of the work, drafted the manuscript, revised it critically for important intellectual content, gave final approval of the version to be published and agreed to be accountable for all aspects of the work.

Acknowledgement: The authors thank Dr. Terence Fargher, who provided insight into and expertise on the use of Antivipmyn for massasauga rattlesnake bites.

Correspondence to: Marissa Laureano, marissa.laureano@medportal.ca 